\title{
Potencialidade da utilização da areia removida em desarenadores de estação de tratamento de esgoto na construção civil, como material alternativo à areia comercial comum
}

\section{Assessment of the potential use of the grit removed in municipal wastewater treatment plants in civil construction as an alternative to the commercial sand}

\author{
Data de entrada: \\ 28/06/2015 \\ - Data de aprovação: \\ 10/02/2016
}

\section{Resumo}

Mesmo com o alto nível de tecnologia envolvido nos processos e operações que compõem as estações de tratamento de esgoto (ETE), a questão da destinação final dos resíduos sólidos removidos no tratamento preliminar de ETE ainda carece de estudos, tanto em pesquisas quanto em projetos de novas estações; visando, principalmente, a utilização dos subprodutos passíveis de aproveitamento. Apesar de não receber a devida importância, uma vez que a prática comum é o lançamento desse tipo de resíduo em aterros sanitários sem a preocupação com reúso, redução, recuperação e impactos ambientais, atualmente, esse resíduo passou a ser considerado um dos problemas no gerenciamento de estações no que se refere ao manuseio, tratamento e destinação final. Nesse contexto, 0 presente artigo tem como objetivo demonstrar a potencialidade da utilização da areia residual removida nos desarenadores do tratamento preliminar de estações de tratamento de esgoto, como agregado para argamassa e concreto não estrutural na construção civil. Esta pesquisa tomou como referência a ETE Monjolinho de São Carlos-SP. Os resultados permitiram constatar que a areia residual apresenta elevada porcentagem de sólidos totais fixos $(96,1 \%)$, alto teor de umidade $(17,3 \%)$ e densidade expressiva de coliformes totais [média de $3,84 \times 10^{7}(100 \mathrm{~mL})^{-1}$ ] e fecais [média de $5,22 \times 10^{5}(100 \mathrm{~mL})^{-1}$ ]. $O$ procedimento de limpeza e secagem da areia utilizada na pesquisa foi eficaz, uma vez que obteve as seguintes eficiências de remoção: cerca de 99,4\% de umidade, 69,3\% de sólidos totais voláteis e 5 log de E.Coli. Após limpeza e secagem da areia residual, diferentes teores desse material foram utilizados na confecção de corpos de prova, que foram submetidos a ensaios de resistências, lixiviação, solubilização e determinação de absorção de água. De forma comparativa, foram realizados os mesmos ensaios com a areia comercial comum (areia de referência), proporcionando uma análise mais clara e completa do estudo. Diante dos resultados de resistências obtidos e considerando a ideia de utilizar a maior proporção de material residual que seria descartado na ETE, recomenda-se a utilização de até $70 \%$ de areia residual como agregado miúdo em argamassas de cimento e cal e concreto magros (não estrutural). Os resultados dos ensaios de lixiviação e solubilização classificaram as argamassas e os concretos preparados com e sem substituição da areia comercial pela areia residual como resíduos classe II A, não perigosos e não inertes.

Palavras-chave: agregado miúdo, areia residual, aproveitamento de areia em ETEs, construção civil, desarenadores, tratamento preliminar. 


\section{Abstract}

Even with the high level of technology involved in the processes and operations that make up the wastewater treatment plants (WWTPS), the question of disposal of solid waste removed in the primary treatment of WWTP still needs studies, both in research as in the design of new plants; aiming mainly the use of byproducts. Although not given due importance, since the common practice is the launch of this type of waste in landfills without concern for reuse, reduction, recovery and environmental impacts, currently, this waste is now considered one of the management problems concerning handling, treatment and disposal. In this context, this article demonstrates the potential use of residual sand removed from grit chambers, which are used in the primary treatment of Wastewater Treatment Plants (WWTPs), as an alternative material to commercial sand, such as aggregate mortar and non-structural concrete in civil construction. This research took as a reference the WWTP Monjolinho of São Carlos-SP. The results indicated that the residual sand has a high percentage of total fixed solids (96.1\%), high moisture content (17.3\%) and significant total coliform [average of $3.84 \times 10^{7}\left(100 \mathrm{~mL}^{-1}\right.$ ] and fecal coliform densities [average of $5.22 \times 10^{5}(100 \mathrm{~mL})^{-1}$ ]. The sand cleaning and drying procedure used in the research was effective, since it achieved the following removal efficiencies: about $99.4 \%$ of moisture, $69.3 \%$ of total volatile solids and 5-log E. Coli. After cleaning and drying the residual sand, different amounts of this material were used to prepare the test specimens, which underwent tensile tests leaching, solubilization and determination of water absorption. For comparative purposes, the same tests with the common commercial sand were performed (reference sand), providing a clearer and more complete analysis of the study. From the results obtained and the resistance considering the idea of using the largest proportion of waste material that would be discarded at the WWTP, it is recommended to use up to $70 \%$ residual sand as fine aggregate in cement and lime mortar and thin concrete (nonstructural). The results of leaching and dissolution tests rated the mortars and concrete prepared with and without replacement of sand by commercial residual waste sand as class II A, and non-hazardous non-inert.

Keywords: construction, fine aggregate, grit chambers, preliminary treatment, residual sand, sand reuse from WWTPs.

\footnotetext{
Nayara Batista Borges (*) - Engenheira Ambiental pela Universidade Federal de Viçosa. Doutora em Hidráulica e Saneamento pela Universidade de São de Paulo - Escola Engenharia de São Carlos.

José Roberto Campos - Engenheiro Civil pela Universidade de São Paulo. Professor titular da Universidade de São Paulo - Escola Engenharia de São Carlos.

Javier Mazariegos Pablos - Engenheiro Elétrico pela Universidade de São Paulo. Professor doutor da Universidade de São Paulo - Escola Engenharia de São Carlos.

Gilcimar Trento Ferreira - Engenheiro Ambiental pela UNICASTELO. Chefe do setor de operação da ETE Monjolinho do Serviço Autônomo de Água e Esgoto (SAAE) São Carlos- SP.

Endereço para correspondência (*): Avenida trabalhador são-carlense, 400, CEP: 13566-590, São Carlos - SP/Brasil. E-mail: naybatistaa yahoo.com.br
} 


\section{INTRODUÇÃO}

Uma das funções do tratamento preliminar é a retenção de sólidos grosseiros: minerais, sementes, cascas de ovos, penas de aves, pedaços de ossos, cabelo e outros, que são genericamente denominados "areia". A finalidade da remoção desse material no tratamento de esgoto é eliminar ou minimizar os efeitos adversos ao funcionamento das partes componentes das instalações componentes da Estação de Tratamento de Esgoto (ETE).

O material removido pelos desarenadores possui, geralmente, entre $35 \%$ e $80 \%$ de sólidos na fase seca e de $1 \%$ a $55 \%$ de sólidos voláteis (WATER ENVIRONMENT FEDERATION, 1998). Segundo os dados disponibilizados, por exemplo, sobre a ETE de Dr. Hélio Seixo de Britto (ETE Goiânia), a porcentagem de sólidos voláteis na areia retida, nos meses de julho a outubro, foi de $41,3 \%$ em relação aos sólidos totais e, nos meses de novembro e dezembro, essa porcentagem foi da ordem de $9 \%$ (SILVIA; CARVALHO, 2007).

Os resíduos removidos nos desarenadores são classificados como classe II A (não perigosos e não inertes), segundo a NBR 10004 (ABNT, 2004), apresentando porcentagens médias de $25,5 \%$ de umidade, densidades médias de $E$. coli de $2,7 \times 10^{6}$ (100 mL) $)^{-1}$ e ovos de helminto de 0,6 ovos g $^{-1}$ (TOMIELLO, 2008; YAMANE 2007).

No Brasil, a prática comum no que se refere ao descarte da areia proveniente de ETEs é dispô-la no próprio terreno da estação (enterramento ou empilhamento) ou encaminhá-la para aterros. De forma geral, não há preocupação relacionada às potencialidades associadas ao seu aproveitamento direto, redução ou recuperação do volume gerado e impactos ambientais. A disposição em aterros brasileiros, além de representar custo da ordem de $\mathrm{R} \$ 160,00 \mathrm{t}^{-1}$ (valor em maio de 2014, contabilizados gastos inerentes ao transporte e disposição), ocupa volume que poderia ser efetivamente destinado aos resíduos domésticos. $\mathrm{A}$ título de comparação, nos Estados Unidos, em algumas grandes ETEs, o resíduo dos desarenadores é incinerado conjuntamente com outros sólidos, tais como: material gradeado e lodos biológicos diversos. Em alguns estados americanos, existem leis ambientais que obrigam a estabilização com cal antes da disposição em aterro sanitário (METCALF; EDDY, 2003).

A utilização da areia removida em desarenadores em ETEs na construção civil surge como opção, com a premissa de que seja realizada sua higienização, com o objetivo de eliminar ou reduzir significativamente a densidade de micro-organismos patogênicos e remover matéria orgânica. Todavia, esse assunto, apesar de promissor, ainda é pouco explorado, pois, além do potencial benefício econômico, implica ganhos no aspecto ambiental, mediante a possível redução que pode ser alcançada na atividade de extração de areia comercial (isto é, empregada na construção civil) de leitos/ margens de rios, que causa intenso dano à qualidade das águas.

Atualmente, há grande preocupação em relação aos resíduos, por se tratar de problema ambiental e também por acarretar gastos cada vez mais elevados para transporte e disposição apropriado desse material. Dessa forma, a utilização desses resíduos para produzir outros materiais pode reduzir o consumo de energia, as distâncias de transporte, como também contribuir para a redução da poluição decorrente.

Há várias pesquisas comprovando a viabilidade técnica da reutilização como agregado de alguns resíduos gerados na construção civil, como areia de fundição, areia de britagem (produto secundário do processo de beneficiamento de pedra britada), entre outros. Outra fonte de matéria-prima utilizada na construção civil é os resíduos do saneamento básico, como o lodo gerado em estações de tratamento de água e ETEs. Pesquisas têm demostrado a potencialidade da utilização desses 


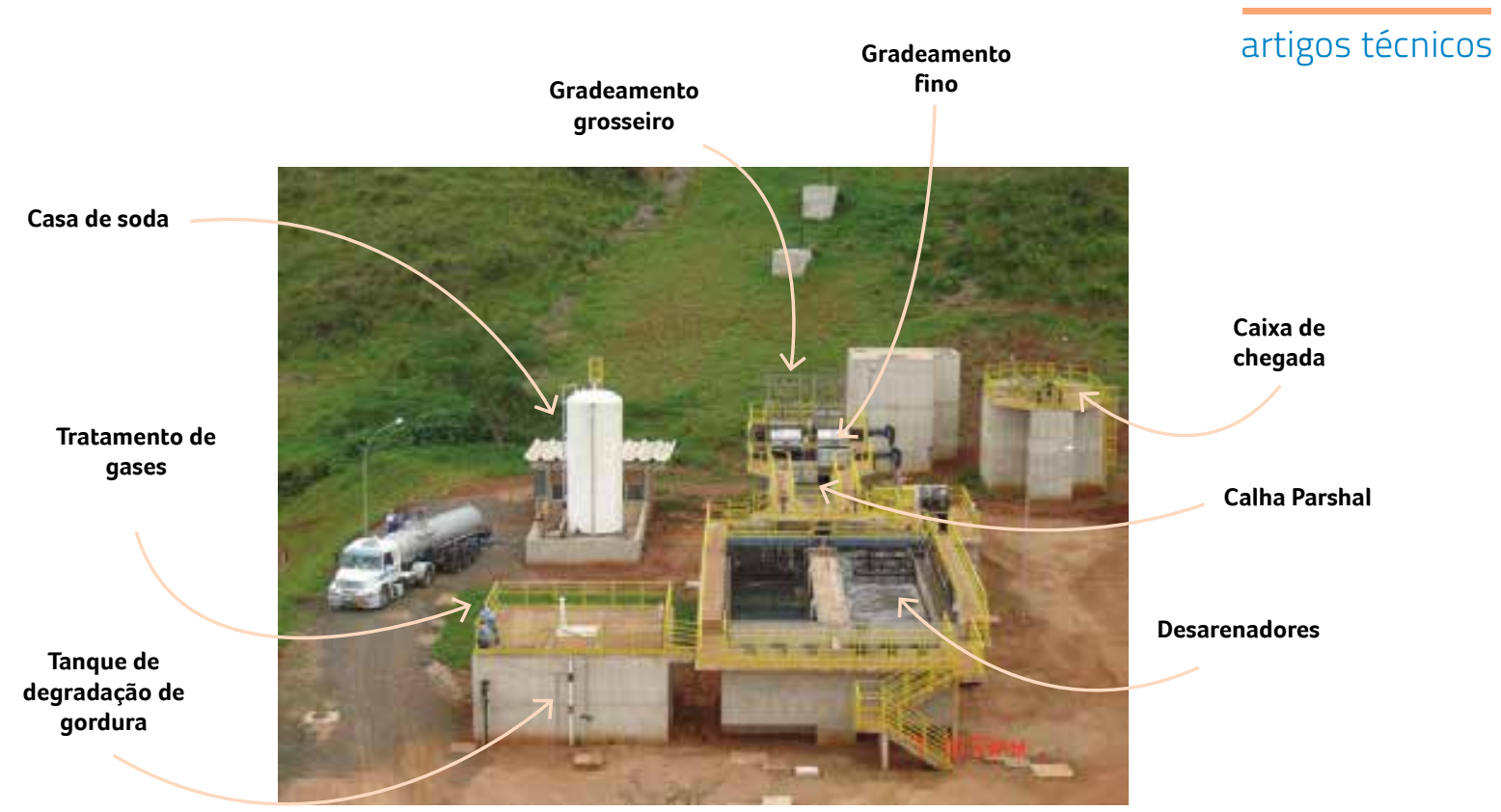

Figura 1 - Unidades e equipamentos componentes do tratamento preliminar da ETE Monjolinho - São Carlos-SP.

resíduos na confecção de concreto ou incorporação em argamassas, em substituição parcial de algum dos seus componentes (cimento ou areia), visando à redução no custo e no impacto ambiental.

Nesse contexto, o presente trabalho busca avaliar a potencialidade do aproveitamento da areia removida em ETEs como agregado miúdo para argamassa e concreto não estrutural na construção civil, após lavagem e secagem.

\section{MATERIAL E MÉTODOS}

\section{Ete Monjolinho - São Carlos-SP}

A pesquisa foi desenvolvida no tratamento preliminar da ETE Monjolinho, localizada na cidade de São Carlos (SP). O sistema de tratamento implantado na ETE tem capacidade para atender à vazão média de $636 \mathrm{Ls}^{-1}$ e vazão máxima de $1.050 \mathrm{Ls}^{-1}$, sendo constituído por tratamento preliminar, seguido por reatores anaeróbios de fluxo ascendente de manta de lodo (UASB), floculação, flotação por ar dissolvido, desinfecção com radiação ultravioleta e pós-aeração. O lodo gerado na flotação e nos reatores UASB é desaguado por centrífugas.
O tratamento preliminar (Figura 1) da referida ETE é constituído por:

- grades mecanizadas do tipo cremalheira com espaçamento entre barras de $2 \mathrm{~cm}$;

- grades mecanizadas do tipo escada com espaçamento livre entre lâminas de $3 \mathrm{~mm}$;

- calha Parshall com garganta de 0,915 m;

- desarenadores aerados com remoção simultânea de areia e de óleos e graxas;

- sistema aeróbio para degradação de óleos e graxas, removidos no desarenador aerado;

- tratamento de gases.

O resíduo sedimentável é removido em intervalos regulares dos desarenadores por bombas submersíveis e encaminhado para equipamentos "classificadores” de areia e, a seguir, para caçamba.

De acordo com os dados operacionais de janeiro de 2012 a março de 2014, a ETE apresentou valor médio de vazão de 527 L.s ${ }^{-1}$, resultando nos seguintes parâmetros para cada desarenador: vazão de ar de $5 \mathrm{~m}^{3} \cdot \mathrm{min}^{-1}$, taxa de aplicação média de $720 \mathrm{~m}^{3} \mathrm{~m}^{-2} \cdot \mathrm{dia}^{-1}$ e tempo de detenção 
hidráulica de $6 \mathrm{~min}$. A quantidade de areia removida, na ocasião da pesquisa, foi de 25 t.mês ${ }^{-1}$, correspondente a $18,3 \mathrm{~kg}\left(1.000 \mathrm{~m}^{3}\right)^{-1}$. Atualmente, o preço pago por tonelada pelo transporte e disposição desse resíduo no aterro sanitário de São Carlos é de cerca de $\mathrm{R} \$ 160,00$ (transporte: $43 \%$ e disposição: 57\%).

\section{CARACTERIZAÇÃO DA AREIA RESIDUAL REMOVIDA NOS DESARENADORES}

Para caracterização da areia residual, foram coletadas seis amostras, em diferentes épocas do ano. Cada amostragem constituiu uma coleta, durante duas horas de operação dos classificadores de areia, em que cerca de $70 \mathrm{~kg}$ de areia foram dispostos sobre lona plástica. A areia foi revolvida e uma amostra de aproximadamente $2 \mathrm{~kg}$, retirada para determinação dos seguintes parâmetros: série de sólidos totais, umidade, coliformes totais e fecais. Após, foi encaminhada à unidade experimental abrigada em uma estufa agrícola com 6,0 $\mathrm{m}$ de comprimento, 4,0 $\mathrm{m}$ de largura e 3,0 $\mathrm{m}$ de altura para procedimento de limpeza e secagem. Os gases exalados foram retirados da unidade por exaustor do tipo axial, de capacidade de 1.500 $\mathrm{m}^{3} \mathrm{~h}^{-1}$ e pressão de serviço de 6 mmca.

Para determinação de coliformes totais e fecais, misturaram-se, durante $5 \mathrm{~min}, 20 \mathrm{~g}$ de areia residual com $200 \mathrm{~mL}$ de água deionizada. Após a mistura, a amostra foi mantida em repouso durante 24 h e, depois desse tempo, o sobrenadante foi analisado de acordo com os Standard Methods for the Examination of Water and Wastewater (APHA, 2005).

Para duas dessas amostras, também foi efetuada determinação da distribuição granulométrica. Após, determinou-se a concentração de sólidos totais voláteis e fixos, para verificar as porcentagens de matéria orgânica e do resíduo inerte das frações retidas nesse ensaio.

\section{DEFINIÇÃO DOS PROCEDIMENTOS DE LIMPEZA E SECAGEM DA AREIA RESIDUAL}

As possibilidades de utilização ou aproveitamento da areia em estado bruto, ou seja, sem lavagem, secagem e classificação, são praticamente inexistentes. Devido a isso, foi realizado procedimento de limpeza e secagem (peneiramento, lavagem e secagem), com o intuito de reduzir a umidade, a matéria orgânica e a densidade de micro-organismos patogênicos, tornando-a segura do ponto de vista microbiológico para as possíveis aplicações desejadas.

Primeiramente, os resíduos coletados foram dispostos em duas baias, durante cinco dias, cada uma com 1,2 m de comprimento e 0,6 $\mathrm{m}$ de largura, para a drenagem/evaporação do líquido (esgoto) coletado com o material. Posteriormente, a areia residual foi peneirada (peneira de abertura de 1,18 mm) para remoção de materiais maiores, tais como: bitucas de cigarro, sementes, pedras, palitos de fósforo, entre outros. Após, efetuou-se lavagem em betoneira (capacidade total do tambor de $63 \mathrm{~L}$ ) com água potável e hipoclorito de sódio, com concentração de $12 \%$, visando à inativação de micro-organismos e possível oxidação da matéria orgânica agregada na areia. Para cada lavagem, foram estabelecidos os seguintes parâmetros: relação areia/água potável de 0,51 , relação da solução de hipoclorito de sódio/água potável de 0,03 e tempo de mistura de $10 \mathrm{~min}$. Por fim, a areia lavada foi disposta em quatro baias (cada uma com 0,6 m de comprimento, 0,6 $\mathrm{m}$ de largura e 0,2 $\mathrm{m}$ de altura total) para secagem durante dez dias. Na Figura 2 estão ilustradas as etapas do procedimento de limpeza e secagem da areia residual.

Após procedimento de limpeza e secagem, foram realizadas para quatro amostras as seguintes determinações: distribuição granulométrica, massa unitária, massa específica aparente, série de 

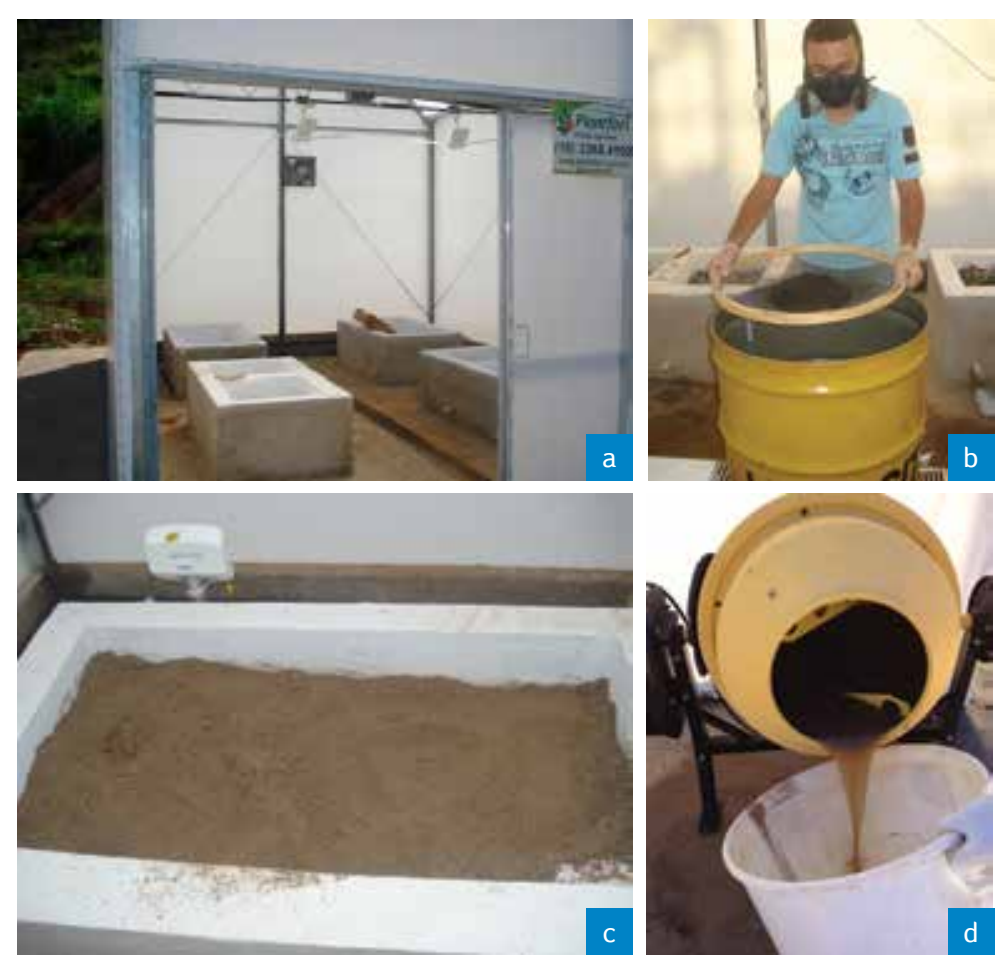

Figura 2 - Etapas da limpeza e secagem do material sedimentável: (a) unidade experimental; (b) peneiramento; (c) secagem; (d) lavagem.

sólidos totais, umidade e coliformes totais e fecais. Tais determinações também foram feitas para areia comercial de referência. Ressalta-se que a areia de referência também foi submetida à etapa de peneiramento (abertura de 1,18 mm), antes da realização das análises.

\section{ENSAIOS: CONCRETO E ARGAMASSAS}

Para ensaios de controle para o concreto, foram confeccionados corpos de prova cilíndricos (100 $\mathrm{mm}$ de diâmetro e $200 \mathrm{~mm}$ de altura) com traço 1:3:2 (cimento:areia:brita), em massa. Os componentes do concreto utilizados na pesquisa foram: cimento Portland do tipo CP-II-E-32, brita $\mathrm{n}^{\circ} 1$ (granulometria variando de 9,5 a $19 \mathrm{~mm}$ ), areias residual e comercial e água (relação água/cimento foi estabelecida na faixa de 0,5 a 0,7).

Foram realizados ensaios utilizando substituição total da areia comum pela areia residual e ensaios com substituição parcial nas proporções de $30 \%$, $50 \%, 70 \%$ e $80 \%$. Nos ensaios com substituição total ( $100 \%$ de areia residual), foram analisadas as idades de cura de 28 dias e 91 dias e os seguintes parâmetros foram avaliados: resistências à compressão axial, conforme a NBR 5739 (ABNT, 1994) e à tração por compressão diametral, segundo determinação da NBR 7222 (ABNT, 1994); absorção de água, conforme a NBR 9778 (ABNT, 2005); lixiviação e solubilização, conforme a NBR 10005 (ABNT, 2004) e a NBR 10006 (ABNT, 2004), respectivamente. Já nos ensaios com substituição parcial, analisou-se apenas a idade de 28 dias e foram verificadas as resistências à compressão axial e à tração por compressão diametral.

Também, foram avaliadas as possibilidades de utilização da areia residual em argamassa para revestimento externo. Para tanto, foram moldados corpos de prova cilíndricos $(50 \mathrm{~mm}$ de diâmetro e $100 \mathrm{~mm}$ de altura) com traço 1:1:6 (cimento:cal hidratada:areia), em massa, e realizados ensaios de resistência à compressão axial, lixiviação e solubilização na idade de 28 dias. 
Tabela 1 - Classificação de argamassas de assentamento e revestimento de paredes e tetos segundo a NBR 13281 (ABNT, 2005).

\begin{tabular}{|c|c|c|c|c|c|}
\hline \multicolumn{7}{|c|}{ Resistência característica (Mpa) } \\
\hline Classe 1 & Classe 2 & Classe 3 & Classe 4 & Classe 5 & Classe 6 \\
\hline$\leq 2,0$ & 1,5 a 3,0 & 2,5 a 4,5 & 4,0 a 6,5 & 5,5 a 9,0 & $\geq 8,0$ \\
\hline
\end{tabular}

Os aglomerantes utilizados foram o cimento Portland CP-II-E-32 e a cal hidratada do tipo $\mathrm{CH}$ -II. As argamassas foram preparadas substituindo a areia comercial pela areia residual nas porcentagens crescentes de 0\%, 30\%, 50\% e 100\%. A relação água/cimento foi estabelecida em 1,2.

A preparação, moldagem e cura dos corpos de prova foram executadas de forma padronizada e seguindo o que prescreve a NBR 5738 (ABNT, 2003), para melhor confiabilidade dos resultados obtidos.

Podem-se definir as resistências características do concreto à compressão $\left(f_{c k}\right)$ e à tração $\left(f_{c t k}\right)$ como valor mínimo estatístico acima do qual ficam situados $95 \%$ dos resultados experimentais, sendo determinadas pelas seguintes equações (ANDOLFATO, 2002):

$$
\begin{aligned}
& f_{c k}=f_{c m}-1,65 \times s \\
& f_{c t k}=f_{c m}-1,65 \times s
\end{aligned}
$$

Em que: $f_{c m}$ é a média aritmética dos valores de $f_{c}$ para o conjunto de corpos de prova ensaiados e $s$ é o desvio padrão.

Para classificar as argamassas em relação ao requisito resistência à compressão, foram utilizadas as características da NBR 13281 (ABNT, 2005), conforme apresentado na Tabela 1.

\section{RESULTADOS}

\section{Caracterização e procedimento de limpeza e} secagem da areia residual

$\mathrm{Na}$ Tabela 2, estão apresentados os resultados das determinações relacionadas com a areia residual removida nos desarenadores, antes e depois do procedimento de limpeza e secagem, e a areia de referência.

De acordo com os dados apresentados na Tabela 2 , verificou-se que:

- Os resíduos, antes do procedimento de limpeza e secagem, apresentaram elevada porcentagem de sólidos totais fixos, alto teor de umidade e densidade expressiva de coliformes totais e fecais, demostrando a necessidade de tratamento com o objetivo de eliminar ou reduzir significativamente a densidade de micro-organismos patogênicos, a fim de tornar a areia segura do ponto de vista microbiológico, bem como diminuir a quantidade de água e material orgânico, viabilizando as possíveis aplicações desejadas.

- O procedimento de limpeza e secagem utilizado foi eficaz, obtendo-se as seguintes eficiências de remoção: 99,4\% de umidade e 69,3\% de sólidos totais voláteis, além de decaimento bacteriano médio de 5 log para Coliformes totais e E.Coli. 
Tabela 2 - Determinações referentes aos resíduos removidos no desarenador antes e após procedimento de limpeza e secagem da areia de referência.

\begin{tabular}{|c|c|c|c|c|}
\hline \multirow{2}{*}{ Parâmetro } & \multirow{2}{*}{ Unidade } & \multicolumn{2}{|c|}{ Areia residual } & \multirow{2}{*}{$\begin{array}{l}\text { Areia referência } \\
\qquad(\mathrm{n}=1)\end{array}$} \\
\hline & & Antes $(n=6)$ & Após $(n=4)$ & \\
\hline Coliformes totais & UFC. $(100 \mathrm{~mL})^{-1}$ & $3,84 \mathrm{E}+07$ & $1,96 \mathrm{E}+02$ & $1,6 \times 10^{3}$ \\
\hline E. coli & UFC. $(100 \mathrm{~mL})^{-1}$ & $5,22 E+05$ & Ausência & Ausência \\
\hline Sólidos totais & (\%) & $85,2 \pm 3,60$ & $99,9 \pm 0,39$ & 99,9 \\
\hline Sólidos totais fixos & (\%) & $96,9 \pm 1,07$ & $99,0 \pm 0,13$ & 99,9 \\
\hline Sólidos totais voláteis & (\%) & $3,1 \pm 1,07$ & $1,0 \pm 0,13$ & 0,1 \\
\hline Porcentagem de umidade & (\%) & $14,8 \pm 3,69$ & $0,10 \pm 0,39$ & 0,1 \\
\hline
\end{tabular}

Nota: $\mathrm{n}=$ número de amostras.

- A areia residual após procedimento de limpeza e secagem apresentou características semeIhantes às da areia de referência, mostrando valores pouco superiores para sólidos totais voláteis, E. coli e umidade.

Na Figura 3, encontram-se os resultados das análises granulométricas da areia residual após limpeza e secagem e da areia de referência, assim como os limites das zonas ótima e utilizável, prescritos na NBR 7211 (ABNT, 2009) para recepção e produção de agregados miúdos. Ressalta-se que, apesar de essa norma não se aplicar a agregados obtidos por processos industriais, como subprodutos, e a materiais reciclados ou mistura desses

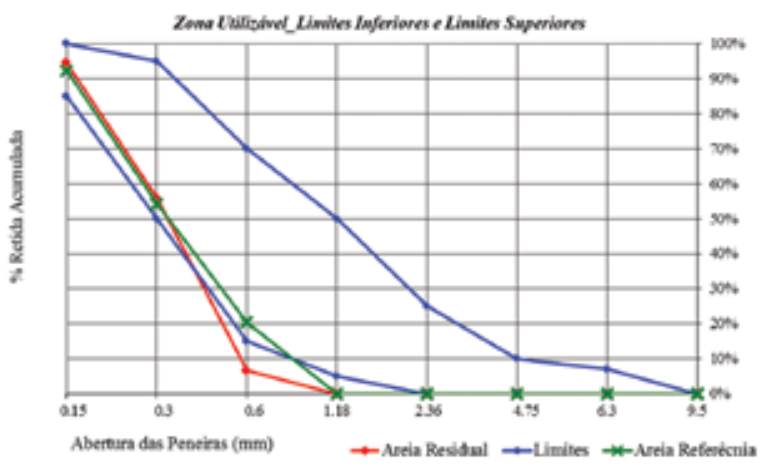

agregados, servirá de subsídio para comparação com material deste estudo.

Nota-se que as curvas granulométricas apresentaram características semelhantes. Para ambas as curvas, a porcentagem acumulada foi menor que o limite inferior (5\%) para abertura de 1,18 mm. A areia residual também apresentou porcentagem acumulada menor que o limite inferior (15\%) para abertura de 0,60 mm. A explicação para tal fato é que foram removidos todos os resíduos com dimensões maiores durante a etapa de peneiramento (peneira de 1,18 $\mathrm{mm}$ ), tanto da areia residual quanto da areia de referência. Essa etapa foi fundamental para reduzir parcela da matéria orgânica da areia residual.

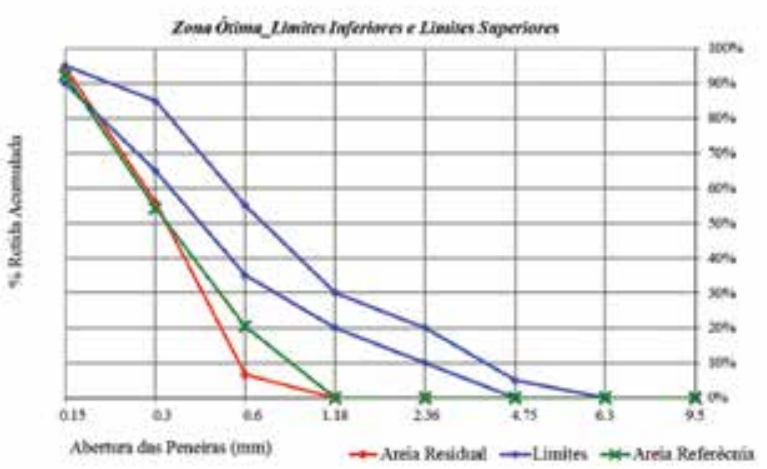

Figura 3 - Análise granulométrica da areia residual após procedimento de limpeza e secagem e da areia de referência e limites da NBR 7211 (ABNT, 2009). 
Destaca-se que podem ser utilizados como agregado miúdo para concreto materiais com distribuição granulométrica diferente das zonas apresentadas na Figura 3, desde que estudos prévios de dosagem comprovem sua aplicabilidade.

Verificou-se menor concentração de resíduos orgânicos nas frações retidas nas peneiras de abertura menor, demostrando que, para reduzir a parcela de matéria orgânica da areia residual, é fundamental a etapa de peneiramento.

$\mathrm{Na}$ Tabela 3, apresentam-se os resultados dos agregados (areia e brita) utilizados na composição do concreto. Como agregado miúdo, utilizaram-se a areia residual (removida nos desarenadores) e a areia de referência e, como agregado graúdo, empregou-se a brita $n^{\circ} 1$.
É importante conhecer as características dos materiais utilizados na composição do concreto, pois elas influenciam a resistência, durabilidade e dosagem do concreto. Conforme os valores apresentados na Tabela 3, verificou-se que a areia residual e a areia de referência apresentaram características bastante semelhantes. Ambas revelaram baixo módulo de finura, indicando a presença de alta porcentagem de matéria fina. Ressalta-se que alta porcentagem de matéria fina exige aumento da água de amassamento e, consequentemente, de cimento, para o mesmo fator água/cimento, tornando o concreto mais dispendioso. Além disso, o material inferior a $0,076 \mathrm{~mm}$ pode misturar-se com o cimento, criando descontinuidade na mistura e reduzindo a resistência do concreto. Por outro lado, o concreto sem o material fino é pouco trabalhável, sujeito à maior permeabilidade e agentes agressivos.

Tabela 3 - Características dos agregados utilizados na composição do concreto.

\begin{tabular}{|c|c|c|c|c|c|}
\hline Parâmetro & Unidade & Norma ABNT & Areia residual & $\begin{array}{l}\text { Areia de } \\
\text { referência }\end{array}$ & $\begin{array}{l}\text { Brita } \\
n^{0} 1\end{array}$ \\
\hline Massa unitária & $\mathrm{kg} \mathrm{L}^{-1}$ & NM 45/06 & 1,45 & 1,60 & 1,57 \\
\hline $\begin{array}{c}\text { Massa específica } \\
\text { aparente }\end{array}$ & $\mathrm{g} \mathrm{cm}^{-3}$ & NM 52/09 & 2,44 & 2,62 & \\
\hline Diâmetro máximo característico & $\mathrm{mm}$ & NBR $248 / 03$ & 1,18 & 1,18 & 6,30 \\
\hline Módulo de finura & & NBR 248/03 & 1,57 & 1,67 & 4,84 \\
\hline
\end{tabular}

Tabela 4 - Resultados dos ensaios de controle para concreto confeccionado com $100 \%$ de areia residual ou $100 \%$ de areia de referência aos 28 e 91 dias de cura.

\begin{tabular}{|c|c|c|c|c|c|c|c|c|}
\hline \multirow{3}{*}{ Parâmetro } & \multicolumn{4}{|c|}{ Areia residual } & \multicolumn{4}{|c|}{ Areia de referência } \\
\hline & \multicolumn{2}{|c|}{ Número de amostras } & \multicolumn{2}{|c|}{ Valor médio } & \multicolumn{2}{|c|}{ Número de amostras } & \multicolumn{2}{|c|}{ Valor médio } \\
\hline & 28 dias & 91 dias & 28 dias & 91 dias & 28 dias & 91 dias & 28 dias & 91 dias \\
\hline $\begin{array}{l}\text { Resistência à compressão } \\
\text { axial (MPa) }\end{array}$ & 20,0 & 10,0 & 9,7 & 9,9 & 5,0 & 5,0 & 19,8 & 22,4 \\
\hline $\begin{array}{l}\text { Resistência à tração por } \\
\text { compressão diametral } \\
\text { (MPa) }\end{array}$ & 16,0 & 8,0 & 1,1 & 1,2 & 4,0 & 4,0 & 2,1 & 2,2 \\
\hline Absorção de água (\%) & 12,0 & 6,0 & 6,2 & 4,9 & 3,0 & 3,0 & 7,5 & 6,8 \\
\hline
\end{tabular}


Tabela 5 - Parâmetros com valores superiores aos máximos estabelecidos na NBR 10004 (ABNT, 2004) no extrato para os corpos de prova, aos 28 e 91 dias de cura.

\begin{tabular}{|c|c|c|c|c|c|c|}
\hline \multirow[b]{2}{*}{ Parâmetro } & \multirow[b]{2}{*}{ Unidade } & \multicolumn{2}{|c|}{28 dias } & \multicolumn{2}{|c|}{91 dias } & \multirow{2}{*}{$\begin{array}{l}\text { Limite máximo } \\
\text { no extrato }\end{array}$} \\
\hline & & $\begin{array}{l}\text { Areia de } \\
\text { referência }\end{array}$ & $\begin{array}{c}\text { Areia } \\
\text { residual }\end{array}$ & Areia de referência & $\begin{array}{l}\text { Areia } \\
\text { residual }\end{array}$ & \\
\hline Alumínio & $\mathrm{mg} \mathrm{Al} \mathrm{L}^{-1}$ & 0,25 & 0,35 & 0,26 & 0,45 & 0,20 \\
\hline Bário & $\mathrm{mg} \mathrm{Ba} \mathrm{L}^{-1}$ & 0,79 & 1,96 & 1,24 & 0,86 & 0,70 \\
\hline Cádmio & $\mathrm{mg} \mathrm{Cd} \mathrm{L}^{-1}$ & 0,004 & 0,054 & 0,017 & 0,042 & 0,005 \\
\hline Chumbo & $\mathrm{mg} \mathrm{Pb} \mathrm{L}^{-1}$ & $<L D$ & 0,25 & 0,20 & 0,10 & 0,01 \\
\hline Ferro total & $\mathrm{mg} \mathrm{Fe} \mathrm{L}^{-1}$ & 0,12 & 0,27 & 0,35 & 0,69 & 0,30 \\
\hline Surfactantes & $\mathrm{mg} \mathrm{LAS} \mathrm{L}^{-1}$ & 0,75 & 0,83 & 0,50 & 0,90 & 0,50 \\
\hline
\end{tabular}

\section{ENSAIOS COM CORPOS DE PROVA}

$\mathrm{Na}$ Tabela 4, encontram-se os resultados de controle para concreto dos corpos de prova confeccionados com $100 \%$ de areia residual e $100 \%$ de areia de referência com idade de ruptura de 28 e 91 dias.

De acordo com os resultados apresentados na Tabela 4, verificou-se que:

- Os corpos de prova confeccionados com areia de referência apresentaram valores de resistência superiores aos fabricados com $100 \%$ de areia residual.

- As resistências à compressão axial e à tração por compressão diametral foram maiores com o aumento da idade de ruptura. No caso da resistência à compressão axial, o aumento médio foi aproximadamente de 2,4\% para areia residual e 11,5\% para areia de referência. Já para a resistência à tração por compressão diametral, o aumento foi de 9,4\% para areia residual e 4,9\% para areia de referência.

- Os ensaios de absorção revelaram que o concreto confeccionado com areia de referência apresentou maior absorção de água que o elaborado com areia residual, para ambos os tempos de cura analisados.
Os resultados dos ensaios de solubilização dos concretos fabricados com $100 \%$ de areia residual e $100 \%$ de areia de referência, aos 28 e 91 dias, foram muito semelhantes entre si, com alguns parâmetros pouco acima do limite máximo estabelecido pelo Anexo G da NBR 10004 (ABNT, 2004), para ambos os corpos de prova, conforme apresentado na Tabela 5.

De acordo com os resultados dos ensaios de lixiviação dos concretos preparados com areia residual e de referência aos 28 e 91 dias de cura, verificou-se que os valores de todos os parâmetros analisados foram inferiores aos limites estabelecidos no extrato de lixiviado Anexo F da NBR 10004 (ABNT, 2004). Portanto, os resultados dos ensaios de lixiviação e solubilização classificaram os concretos confeccionados com areia residual e areia de referência, para ambas as idades analisadas, como resíduos classe II A, não perigosos e não inertes.

Visando a aumentar a resistência à compressão axial dos corpos de prova, foi avaliada a substituição parcial da areia residual por areia comercial comum. Na Tabela 6, encontram-se os resultados dos ensaios de resistência à compressão axial e à tração por compressão diametral, que utilizaram as seguintes porcentagens da areia residual: $100 \%, 80 \%, 70 \%, 50 \%, 30 \%$ e $0 \%$, como agregado miúdo na preparação do concreto. 
Tabela 6 - Resultados dos ensaios de resistência dos corpos de prova confeccionados com substituição total e parcial da areia comercial por areia residual comum aos 28 dias de cura.

\begin{tabular}{|c|c|c|c|c|c|c|}
\hline \multirow{3}{*}{ Parâmetro } & \multicolumn{6}{|c|}{ Resistência à compressão axial (MPa) } \\
\hline & $100 \% A R+0 \% A C$ & $80 \% A R+20 \% A C$ & $70 \% A R+30 \% A C$ & $50 \% A R+50 \% A C$ & $30 \% A R+70 \% A C$ & $0 \% A R+100 \% A C$ \\
\hline & $n=20$ & \multicolumn{5}{|c|}{$n=5$} \\
\hline Mínimo & 6,8 & 10,8 & 12,3 & 13,6 & 17,0 & 19,6 \\
\hline Máximo & 12,5 & 11,0 & 13,4 & 15,7 & 18,1 & 20,1 \\
\hline Média aritmética & 9,7 & 10,9 & 12,8 & 14,9 & 17,4 & 19,8 \\
\hline Mediana & 9,1 & 11,0 & 12,8 & 15,2 & 17,1 & 19,8 \\
\hline Desvio padrão & 1,4 & 0,1 & 0,5 & 0,7 & 0,4 & 0,2 \\
\hline fck & 7,3 & 10,8 & 12,0 & 13,7 & 16,7 & 19,5 \\
\hline \multirow{3}{*}{ Parâmetro } & \multicolumn{6}{|c|}{ Resistência à tração por compressão diametral (MPa) } \\
\hline & $100 \% A R+0 \% A C$ & $80 \% A R+20 \% A C$ & $70 \% A R+30 \% A C$ & $50 \% A R+50 \% A C$ & $30 \% A R+70 \% A C$ & $0 \% A R+100 \% A C$ \\
\hline & $n=16$ & \multicolumn{4}{|c|}{$n=3$} & $n=4$ \\
\hline Mínimo & 0,8 & 1,6 & 1,7 & 1,6 & 1,8 & 1,6 \\
\hline Máximo & 1,5 & 2,0 & 2,0 & 1,8 & 2,0 & 2,4 \\
\hline Média aritmética & 1,1 & 1,7 & 1,8 & 1,7 & 1,9 & 2,1 \\
\hline Mediana & 1,1 & 1,6 & 1,7 & 1,8 & 1,8 & 2,2 \\
\hline Desvio padrão & 0,2 & 0,2 & 0,1 & 0,1 & 0,1 & 0,3 \\
\hline fctk & 0,8 & 1,4 & 1,5 & 1,6 & 1,7 & 1,6 \\
\hline
\end{tabular}

Notas: $\mathbf{n}=$ número de amostras. $A R=$ areia residual. $A C=$ areia comercial.

De acordo com os resultados apresentados na Tabela 6 , verificou-se que:

- Houve acréscimo nos valores de $f_{c k}$ e $f_{c t k}$ à medida que se aumentou a quantidade de areia comercial. No caso da resistência característica à compressão, os aumentos em relação aos ensaios com $100 \%$ de areia residual foram: $46,6 \%, 63,7 \%, 86,9 \%, 127,1 \%$ e $165,1 \%$, respectivamente, para as seguintes porcentagens de areia comercial adicionada: $20 \%, 30 \%, 50 \%, 70 \%$ e $100 \%$. Para os valores de $f_{\text {ctk }}$, para as mesmas proporções de areia comum adicionadas, os aumentos foram de $69,3 \%, 89,0 \%, 93,6 \%, 109,9 \%$ e $97,0 \%$.

- A resistência do concreto à tração variou entre $8,2 \%$ (100\% de areia comercial) e 12,8\% (substituição de $20 \%$ e $30 \%$ de areia residual por comercial) da resistência à compressão.

- Os resultados de resistência do concreto preparado com a mistura de areia residual com areia comercial comum em todas as proporções analisadas foram satisfatórios para utilizações sem função estrutural, tendo em vista que seus valores de $f_{c k}$ foram superiores a $10 \mathrm{MPa}$ - limite mínimo previsto na NBR 15116 (ABNT, 2004).

- Com os resultados referentes à resistência característica à compressão $\left(\mathrm{f}_{\mathrm{ck}}\right)$, uma proporção de $80 \%$ de areia residual e $20 \%$ de areia comercial poderia ser utilizada (maior que $10 \mathrm{MPa}$ ); contudo, por segurança, seria mais apropriado considerar a proporção de $70 \%$ de areia residual e $30 \%$ de areia comercial. 
Tabela 7 - Resultados dos ensaios de resistência das argamassas preparadas com substituição total e parcial de areia residual por areia de comercial comum aos 28 dias de cura.

\begin{tabular}{|c|c|c|c|c|}
\hline \multirow{3}{*}{ Parâmetro } & \multicolumn{4}{|c|}{ Compressão axial (MPa) } \\
\hline & $\begin{array}{c}100 \% A C+ \\
0 \% A R\end{array}$ & $\begin{array}{c}70 \% \mathrm{AC}+ \\
30 \% \mathrm{AR}\end{array}$ & $\begin{array}{c}50 \% A C+ \\
50 \% A R\end{array}$ & $\begin{array}{c}0 \% \mathrm{AC}+ \\
100 \% \mathrm{AR}\end{array}$ \\
\hline & \multicolumn{4}{|c|}{$n=4$} \\
\hline Mínimo & 6,0 & 5,7 & 5,2 & 5,0 \\
\hline Máximo & 8,3 & 6,0 & 7,1 & 5,9 \\
\hline Média aritmética & 7,4 & 5,8 & 6,2 & 5,4 \\
\hline Mediana & 7,7 & 5,8 & 6,3 & 5,3 \\
\hline Desvio padrão & 0,9 & 0,1 & 0,7 & 0,3 \\
\hline fck & 5,97 & 5,61 & 5,02 & 4,82 \\
\hline
\end{tabular}

Notas: $\mathbf{n}=$ número de amostras. $A R=$ areia residual $. A C=$ areia comercial

$\mathrm{Na}$ Tabela 7, estão apresentados os resultados das resistências à compressão axial, aos 28 dias, das argamassas preparadas com substituição da areia comercial pela areia residual nas porcentagens crescentes de $0 \%, 30 \%, 50 \%$ e $100 \%$.

De acordo com os resultados apresentados na Tabela 7, verificou-se que:

- Houve redução da resistência à compressão axial à medida que aumentou a substituição da areia comercial pela areia residual. As reduções em relação às argamassas sem incorporação de areia residual (100\% AC + 0\% AR) foram de aproximadamente $6,0 \%, 15,9 \%$ e 19,2\%, para, respectivamente, as adições de $30 \%, 50 \%$ e $100 \%$ de areia residual.

- Todas as argamassas avaliadas foram classificadas como classe 4, de acordo com a NBR 13281 (ABNT, 2005) (Tabela 1), para assentamento e revestimento de paredes e tetos, pois as resistências características à compressão, aos 28 dias, foram superiores a 4,0 MPa e inferiores a 6,0 MPa.

Os resultados dos ensaios de solubilização das argamassas preparadas com substituição da areia comercial pela areia residual nas porcentagens de $0 \%, 30 \%, 50 \%$ e $100 \%$, aos 28 dias, foram muito semelhantes entre si, com alguns parâmetros pouco acima do limite máximo estabelecido pela NBR 10004 (ABNT, 2004), conforme apresentado na Tabela 8.

De acordo com os resultados de lixiviação das argamassas preparadas com substituição da areia comercial pela areia residual nas porcentagens de 0\%, 30\%, 50\% e $100 \%$, aos 28 dias, verificou-se que os valores de todos os parâmetros analisados foram inferiores aos limites estabelecidos no extrato de lixiviado. Portanto, os resultados dos ensaios de lixiviação e solubilização classificaram essas argamassas como resíduos classe II A, não perigosos e não inertes. 
Tabela 8 - Parâmetros superiores aos valores máximos no extrato para os corpos de prova aos 28 dias de cura.

\begin{tabular}{|c|c|c|c|c|c|c|}
\hline Parâmetro & Unidade & $\begin{array}{c}100 \% \text { AC+ } \\
0 \% \text { AR }\end{array}$ & $\begin{array}{c}70 \% \text { AC+ } \\
30 \% \text { AR }\end{array}$ & $\begin{array}{c}50 \% \text { AC+ } \\
50 \% \text { AR }\end{array}$ & $\begin{array}{c}0 \% \text { AC+ } \\
100 \% \text { AR }\end{array}$ & $\begin{array}{l}\text { Limite máximo } \\
\text { no extrato }\end{array}$ \\
\hline Alumínio & mg Al.L-1 & 0,37 & 0,40 & 0,48 & 0,76 & 0,20 \\
\hline Bário & mg Ba.L-1 & 2,22 & 2,59 & 3,89 & 2,19 & 0,70 \\
\hline Cádmio & $\mathrm{mg} \mathrm{Cd.L-1}$ & 0,017 & 0,015 & 0,021 & 0,018 & 0,005 \\
\hline Chumbo & $\mathrm{mg} \mathrm{Pb.L-1}$ & 0,08 & 0,06 & - & - & 0,01 \\
\hline Cianetos & $\mathrm{mg} \mathrm{CN}-. \mathrm{L}-1$ & - & 0,076 & 0,118 & 0,108 & 0,07 \\
\hline Fenóis totais & $\mathrm{mg} \mathrm{C6H5OH.L-1}$ & 0,031 & 0,122 & 0,207 & 0,023 & 0,010 \\
\hline Nitratos & $\mathrm{mg} \mathrm{N.L-1}$ & - & - & 13,43 & 21,68 & 10,00 \\
\hline Surfactantes & mg LA. L-1 & - & - & 0,75 & 1,25 & 0,50 \\
\hline
\end{tabular}

\section{VIABILIDADE ECONÔMICA DO}

\section{APROVEITAMENTO DA AREIA RESIDUAL}

A Tabela 9 mostra a estimativa total para o aproveitamento da areia removida nos desarenadores da ETE Monjolinho. Ressalta-se que para estimativa considerou-se a produção média de areia removida nos desarenadores da estação, de 25 t.mês ${ }^{-1}$ (dados disponibilizados em maio de 2014 pela gerência do Serviço Autônomo de Água e Esgoto - SAAE de São Carlos).

Conforme os dados apresentados na Tabela 9, o custo estimado para a ETE Monjolinho aproveitar a areia residual removida nos desarenadores seria em torno de $\mathrm{R} \$ 5.357,43$ por mês. Desse valor, deve ser descontado o retorno financeiro que a areia trará para a estação.
De acordo com os dados do Sistema Nacional de Pesquisa de Custos e Índices da Construção Civil, o preço da areia fina, no estado de São Paulo, é em torno de $\mathrm{R} \$ 56,00 . \mathrm{m}^{-3}$, sem considerar o valor do transporte (maio de 2014). Com base no resultado da massa específica da areia residual de 1,45 kg. $\mathrm{L}^{-1}$ (Tabela 3 ), tem-se que o preço da tonelada de areia possível para aproveitamento seria de $\mathrm{R} \$ 38,62$.

$\mathrm{Na}$ Tabela 10, apresenta-se a comparação entre as despesas com a areia removida nos desarenadores da ETE Monjolinho (custo mensal da quantidade de areia a ser transportada e disposta no aterro sanitário) e o custo para possível aproveitamento dessa areia. Ressalta-se que, no cálculo do valor agregado da areia residual, se considerou a taxa de $0,1 \%$ de material não aproveitável (sólidos removidos na etapa de peneiramento). 
Tabela 9 - Custo total para aproveitamento da areia residual na ETE Monjolinho - São Carlos-SP (maio de 2014).

\begin{tabular}{|c|c|c|}
\hline Discriminação & $\begin{array}{l}\text { Custo por tonelada } \\
\left.\text { (RS. } . t^{-1}\right)\end{array}$ & Custo ETE Monjolinho (RS.mês $\left.{ }^{-1}\right)$ \\
\hline Operação & 190,36 & $4.759,00$ \\
\hline Implantação & 21,76 & 544,03 \\
\hline Manutenção & 2,18 & 54,40 \\
\hline Total & - & $5.357,43$ \\
\hline
\end{tabular}

Tabela 10 - Comparação entre possíveis alternativas para areia removida na ETE Monjolinho: aproveitamento e disposição em aterros em R\$.mês ${ }^{-1}$ (maio de 2014).

\begin{tabular}{|c|c|c|}
\hline \multicolumn{1}{|c|}{ Alternativa para areia } & Custo & \multicolumn{1}{c}{ Benefício } \\
\hline Aproveitamento & $5.357,43$ & 868,97 \\
\hline Disposição em aterro sanitário & $4.000,00$ & - \\
\hline
\end{tabular}

De acordo com os resultados apresentados na Tabela 10, verificou-se que o aproveitamento da areia resultou em maiores custos que sua disposição em aterro sanitário. Ressalta-se que essa comparação é específica para cada ETE, tendo em vista que envolve o custo do transporte, o qual é diretamente proporcional à distância entre a estação e o aterro credenciado para receber esse tipo de resíduo, e o custo da disposição. Segundo informações da Gerência, a ETE Monjolinho apresentou custo total para dispor a areia em aterros sanitários inferior aos valores disponibilizados por outras ETES da região, que variou na faixa de 200,00 a 250,00 R\$.t-1. Portanto, sob ponto de vista econômico, a vantagem do aproveitamento da areia está condicionada ao porte da ETE e a distância da mesma ao aterro sanitário, sendo mais vantajosa para ETEs de grande porte (maior valor do benefício em função da maior produção de areia) e situadas em locais onde os aterros sanitários são mais distantes.

\section{CONCLUSÕES}

- Verificou-se a viabilidade da utilização da areia residual, removida nos desarenadores de ETEs, como agregado miúdo na incorporação de argamassas para revestimento e preparação de concreto não estrutural, desde que seja submetida ao procedimento de limpeza e secagem. Esse procedimento tem como objetivo reduzirsignificativamente a densidade de micro-organismos patogênicos e remover matéria orgânica, uma vez que esse tipo de resíduo apresentou alto teor de umidade (17,3\%), quantidade significativa de sólidos totais voláteis $(3,9 \%)$ e densidades expressivas de coliformes totais $\left[3,84 \times 10^{7}\left(100 \mathrm{~mL}^{-1}\right] \mathrm{e}\right.$ fecais $\left[5,22 \times 10^{5}(100 \mathrm{~mL})^{-1}\right]$. 
- O procedimento de limpeza e secagem da areia residual adotado nesta pesquisa foi eficaz, uma vez que obteve as seguintes eficiências de remoção: em torno de 99,4\% de umidade, $69,3 \%$ de sólidos totais voláteis e $5 \log$ de E. coli. Tal procedimento envolveu a implantação de uma edificação coberta, do tipo agrícola, e compreendeu etapas de peneiramento, lavagem e secagem da areia residual.

- Foi comprovada a viabilidade técnica - a partir das resistências à compressão e à tração diametral - e ambiental da potencialidade de aproveitamento da mistura da areia residual com areia comercial na construção civil.

- Os resultados dos ensaios de resistência à compressão das argamassas demostraram que, independentemente da proporção das areias utilizadas, todos os corpos de prova foram classificados como P4 (resistência à compressão na faixa de 4,0 a 6,5 $\mathrm{MPa}$ ), de acordo com os requisitos da NBR 13281 (ABNT, 2005).

- Diante dos resultados de resistências obtidos e considerando a ideia de utilizar a maior proporção de material residual que seria descartado na ETE, tendo em vista que os resíduos são um problema no gerenciamento de estações no que se refere ao manuseio, tratamento e destinação final, recomendase a utilização de $70 \%$ de areia residual como agregado miúdo em argamassas de cimento e cal e concreto magro (não estrutural).

- Os resultados dos ensaios de lixiviação e solubilização classificaram as argamassas e os concretos confeccionados com areia residual e areia de referência como resíduos classe II A, não perigosos e não inertes. Os dados apresentados nesta pesquisa alertam para a necessidade de promover discussão sobre os limites da norma NBR 10004 (ABNT,
2004) quanto aos parâmetros vigentes de determinados elementos em matérias-primas destinadas à construção civil.

- Também, constatou-se que o aproveitamento da areia residual no preparo de concretos e argamassaséumaalternativaambientalmente correta, uma vez que promove redução de quantidades consideráveis desse material a ser dispostas em aterros ou devolvidas, bem como reduções significativas no consumo de agregados naturais.

- Sob o ponto de vista econômico, a vantagem do aproveitamento dos resíduos removidos nos desarenadores está condicionada ao porte da ETE e a distância da mesma ao aterro sanitário.

- Por fim, diante dos resultados obtidos nesta pesquisa e priorizando as questões ambientais, tecnológicas e científicas, recomenda-se, para desenvolvimento de trabalhos futuros, que sejam realizados estudos complementares dos corpos de prova confeccionados com areia residual para verificação da sua durabilidade, entre eles: resistência mecânica a médio e longo prazo, com idade de pelo menos 91 dias; resistência a sulfatos; e resistência à penetração de cloretos.

\section{AGRADECIMENTOS}

Os autores agradecem à Fundação de Amparo à Pesquisa do Estado de São Paulo (Fapesp) pelo auxílio financeiro e incentivo à pesquisa (Processo n 2011/5134-6); à administração do SAAE e à equipe técnica da ETE Monjolinho de São Carlos pela ajuda prestada durante toda a pesquisa; e aos técnicos dos Laboratórios de Saneamento e de Construção Civil da Universidade de São Paulo em São Carlos pela disposição, estímulo e auxílio durante a realização das análises e ensaios. 


\section{REFERÊNCIAS}

Associação Brasileira De Normas Técnicas (1998). NBR 67: Concreto - Determinação da consistência pelo abatimento do tronco de cones. Rio de Janeiro.

NBR 248: Agregados - Determinação da composição granulométrica. Rio de Janeiro, RJ, 2003.

NBR 5738: Concreto - Procedimento para moldagem e cura de corpos-de-prova. Rio de Janeiro, RJ, 2003.

. NBR 10004: Resíduos sólidos - Classificação - Procedimentos. Rio de Janeiro, RJ, 2004.

NBR 10005: Lixiviação de resíduos - Procedimentos. Rio de Janeiro, RJ, 2004.

NBR 10006: Solubilização de resíduos - Procedimentos. Rio de Janeiro, RJ, 2004.

. NBR 15116: Agregados reciclados de resíduos sólidos da construção civil - Utilização em pavimentação e preparo de concreto sem função estrutural - Requisitos. Rio de Janeiro, RJ, 2004.

NBR 9778: Argamassa e concreto endurecidos - Determinação da absorção de água, índice de vazios e massa específica. Rio de Janeiro. 2005.

. NBR 13281: Argamassa para assentamento e revestimento de paredes e tetos - Requisitos. Rio de Janeiro. 2005.

NM 45: Agregados - Determinação da massa unitária e do volume de vazios. Rio de Janeiro. 2006.

NBR 5739: Concreto - Ensaios de compressão de corpos-de-prova cilíndricos. Rio de Janeiro, RJ, 2007.

NM 52: Agregado miúdo - Determinação da massa específica e massa específica aparente. Rio de Janeiro. 2009.

NBR 7211: Agregados para concreto - Especificação. Rio de Janeiro. 2009.
NBR 7222: Argamassa e concreto - Determinação da resistência à tração por compressão diametral de corpos-de-prova cilíndricos. Rio de Janeiro, RJ, 2011.

APHA - AMERICAN PUBLIC HEALTH ASSOCIATION, AWWA AMERICAN WATER WORKS ASSOCIATION, WEF - WATER ENVIRONMENT FEDERATION. 2005. Standard methods for the examination of water and wastewater. $21^{\mathrm{a}}$ ed. APHA, AWWA, WEF, Washington, DC, EUA.

BORGES, N.B. Aproveitamento dos resíduos gerados no tratamento preliminar de estações de tratamento de esgoto.2014. 240 f. Tese (Doutorado em Engenharia) - Escola de Engenharia de São Carlos, Universidade de São Paulo, São Carlos, 2014.

METCALF; EDDY. Wastewater engineering: Treatment disposal and reuse. 4th ed. New York: McGraw-Hill Inc. 1819p. 2003.

SILVA, M. F.; CARVALHO, E. H. Otimização do tratamento preliminar da ETE-Goiâna. In: CONGRESSO BRASILEIRO DE ENGENHARIA SANITÁRIA E AMBIENTAL, 24., 2007, Belo Horizonte. Anais... Belo Horizonte:ABES. 2007.

TOMIELLO, E. C. Análise dos resíduos sólidos de desarenador do tratamento preliminar de esgotos sanitários da Cidade de Maringá - PR. Maringá - PR. 2008.130 f. Dissertação (Mestrado em Engenharia Urbana). Universidade Estadual de Maringá, Maringá, 2008.

WATER ENVIRONMENT FEDERATION (1998) Design of municipal wastewater treatment plants. Water Environment Federation of practice n.8 4.ed v2.Alexandrina, USA: Water Environment Federation and American Society of Civil Engineers.

YAMANE, L. H. Avaliação da higienização do resíduo de caixa de areia de estações de tratamento de esgoto. 2007. 148 f. Dissertação (Mestrado em Engenharia Ambiental). Universidade Federal do Espírito Santo, Vitória, 2007. 